\title{
Sports Arena vs. Crowd Psychology - A Psychosocial Analysis of Polish Football Fans' Participation in UEFA EURO 2012
}

\footnotetext{
Authors' Contribution:

A - Study Design

B - Data Collection

C - Statistical Analysis

D - Data Interpretation

E - Manuscript Preparation

$\mathrm{F}$ - Literature Search

G - Funds Collection
}

\section{Lesław Kulmatycki}

Department of Humanities and Health Promotion, University School of Physical Education, Wroclaw, Poland

Key words: crowd psychology, sports arena, football, fans

\begin{abstract}
With reference to the arena in the ancient Greek ritual theater, the Roman circus, or later the medieval arena as the venue of tournaments of knights, the author recalls the changeability of social functions of public spectacles. Together with the expansion of corporeality and the spirit of competition that started at the beginning of the 20th century, when a sports arena became a place of testing human physical possibilities, also the idea of a modern football stadium is born.

The aim of this paper is to synthesize psychosocial aspects of Polish fans' participation in UEFA EURO 2012.

In his paper of a theoretical character the author raises three specific questions regarding the reception of the European Football Championships, the greatest sports event ever held in Poland. Were football matches not changed into a manifestation of the need for ludic affiliation and social emotions which cannot find other means of expression? Were the great expectations not a kind of therapy to compensate for national complaints? And did Poland's matches against certain national teams become a surrogate method to eliminate negative emotions by referring to the metaphor of pseudo-patriotic war against historical enemies? Were the Polish fans' expectations for their team's success not too high, taking into consideration the football abilities of the team?

The author analyzed fans' reactions in terms of the assumptions of crowd psychology established by Le Bon. He proves that, on the one hand, fans wanted to demonstrate Europe they were not worse than others and their team could win, too. On the other hand, fans wanted to have much fun regardless of the result, that is to see how it was to be loyal fans of their favorite team. There is also an alarming trend in the attitudes assumed by Polish fans who underline the patriotic and nationalistic context.
\end{abstract}

Word count: 3.649

Tables: 0

Figures: 0

References: 20

Received: January 2013

Accepted: February 2013

Published: March 2013

Corresponding author:

dr hab. Lesław Kulmatycki, prof. AWF

University School of Physical Education in Wrockaw, Dep. of Humanities and Health Promotion

51-629 Wroclaw, Poland, ul. Rzeźbiarska 4, pok. 3/14

Phone: +4871 3457-36-18

E-mail: leslaw.kulmatycki@awf.wroc.pl 


\section{From the Ritual Amphitheater to the Football Arena}

In the ancient Greek theater, the arena or amphitheater, to be exact, was an open-air venue whose auditorium was arranged in a semicircle on a slope of a hill with stone seating tiers. The amphitheater originates from the tradition of religious ceremonies, particularly those of Dionysus. This kind of ceremonies and rites were meant for the general public as all the poleis could take part in them without limits [1]. The dominating spirit was of an aesthetic and hedonistic character, whereas the arena in the Roman world adopted another dimension: it became agonistic and utilitarian. The prevailing spirit became the one of fights, tournaments and knightly performances. During religious domination all physical activities of hedonistic nature were discredited. This is the spirit dominating in arenas in the Middle Ages, with additional motifs of asceticism and religious obedience. Other kinds of actors performed in the circus; this particular mass form of performing arts with the predominating spirit of showing off asceticism meant to get applause. There was also a clearly visible need for entertainment and fun [2]. This need in its modern form dates back to 18th century England. In that period the philosophical trend which dominated in European culture was of an intellectual and rational character, which meant that people cared more of their minds than bodies. Since the beginning of the 20th century, corporeality and the spirit of competition have been taking a predominant position, which means that the role of body fitness has been growing. Already in 1863, the first rules of the game of football were established and are known as "Cambridge rules". Over time sport has become an integral part of culture, mass culture, to be exact $[3,4]$. Therefore, there is an urgent need for more arenas, bigger and bigger, until they become stadiums of monstrous dimensions, where people actually feel to be a part of something extraordinary when modern gladiators appear on the pitch to participate in sporting events held at regular intervals, which achieve the rank of global spectacles [5]. These spectacles include championships in the most ludic of sports that is football, also called soccer. The most prestigious of them are the Champions League, the World Cup and the UEFA European Football Championship, the last one held in Poland and Ukraine in 2012.

\section{Arenas, Gladiators and Crowds}

A sports arena is a venue of specific architecture and in itself does not mean much. It wakes up and becomes full of life only when crowds of people fill it up, not just few fans or supporters, but huge groups of people who create a sort of human critical stadium mass [6].

First, I will make some observations about sport in the contemporary world. Contemporary sport is a combination of all the aforementioned sports dimensions; here and there it still manages to maintain the façade motto of "the spirit of pure and noble competition", but it is clearly visible that this is only a pseudo-didactic slogan which tends to be used only in school talks on sport propagating the Olympic spirit. Although contemporary sport has something in common with the spirit of noble knight tournaments or circus performances, it may also be a form of game or fun, entertainment or spectacle, recreation or passion, noble competition or gambling, festival or even religion. It can also be an expression of patriotism or political views. Reflections on UEFA EURO 2012 can be divided into three categories: organizational, sports results and social reaction. The newly built arenas turned out to be quite good, the Polish gladiators let their fans down, what about the crowds? In this paper, I am interested in the last issue. What about to the crowds in EURO 2012 ?

It is not difficult to note that 21 st century sport is mainly directed to either pure entertainment and commerce or politics. To a great extent, EURO 2012 highlighted what contemporary sport is when it exceeds its health, mass and popular dimensions. During the tournament the approach to sport was mainly of two types: hedonistic and nationalist-patriotic. Both approaches are manifested in specific rites adopted by their followers. They are both directed to objectives that have nothing in common with sport; they aim at gaining either financially or politically and thus increasing their prestige. That means that in both cases the organizational scale has to be calculated so as to attract a great number of spectators. Both types of profits are worthwhile only if there is mass participation, that is why the quite pejorative term 'crowd' was used in the title. I do not like to use it, because I associate it with the gloomiest pages of world history. According to Le Bon 'crowd' 
means a gathering of individuals of whatever nationality, profession, or sex and chance that may have brought them together [7, p. 7] and what is even worse, continued the French thinker, little adapted to reasoning, crowds, on the contrary, are quick to act. As the result of their organisation, their strength has become immense. [7, p. 9] The disappearance of conscious personality and the turning of feelings and thoughts in a definite direction, which are the primary characteristics of a crowd. A collective mind is formed, doubtless transitory, but presenting very clearly defined characteristics [7, p. 13]. That means that this potential has also the ability to do great things. Football matches exactly meet the expectations of organizers in terms of the objectives of both approaches. Therefore, the last football championship is a good opportunity to discuss this phenomenon from the perspective of Wrocław experience, one of the host cities.

\section{The Questions of Polish Fans' Participation in Euro 2012}

The aim of this paper is to synthesize psychosocial aspects of Polish fans' participation in EURO 2012. The author in his paper of a theoretical character raises three specific questions regarding the reception of the European Football Championships, the greatest sports event ever held in Poland.

Were football matches not changed into manifestation of the need for ludic affiliation and social emotions which cannot find other means of expression?

Were the great expectations not a kind of therapy to compensate for national complaints? And did Poland's matches against certain other national teams become a surrogate method to eliminate negative emotions by referring to the metaphor of pseudo-patriotic war against historical enemies?

Were the Polish fans' expectations for their team's success not too high, taking into consideration the football abilities of the team?

The answer to each question is viewed as an expression of one of the three approaches to sport.

\section{A Hedonistic Approach - a Carnival Experience}

Large-scale sporting events have their own dramaturgical principles, with a long overture which starts a long time before the proper 'sporting spectacle' has its opening; sometimes the preparation period lasts for weeks or months like, for example, an analysis of each national team of the group which comprised Poland. The preparation for the event itself usually lasts long and has its time schedule and structure. Due to the theatralization of football matches, which includes a stage, protagonists, fixed time of the spectacle and even scenic design comprising certain symbols in the background, also audience is indispensable. The more, the better - millions of spectators. The tournament has the characteristics of a great festival, like a carnival, during which there are more events, not just one. When football carnival focuses on a purely entertainment experience, on the experience based on sensuous perception, to be exact, certain emotions are expected to explode. They are the essence of the spectacle. The climax that is expected is a state of excitation, or even a state of stupefaction or ecstasy. Before the match, the atmosphere of growing tension and the saturation of public space with gadgets, team logos or body painting are preliminary customs that prepare the participants for the rite itself, i.e. the match [8]. Roger Caillos, a French philosopher and sociologist, writes that this sort of spectacle provides an opportunity to get rid of social conventionalities. An individual can lose oneself in the crowd. According to Caillos, multiplicity, i.e. hundreds and thousands of other individuals at the same time and place, gives an opportunity to experience the 'true personality' [9]. The phenomenon can be categorized as a specific psychotherapeutic process, when a contact with the so called spectator's pre-personality occurs. Undoubtedly, mass scale contemporary sport knows exactly how to increase such needs [10, 11]. Organizers purposely introduce carnivalization of the football tournament. Therefore, it is important not to limit the ludic experience to the people who already have tickets, but include a large number of would-be supporters [6]. In order to share the fan experience with as many people as possible, 'fan zones' were invented; the atmosphere prevailing there is very close to that in a stadium; it imitates the tension and rite, where the same gadgets, masks, shouts, gestures and songs are to guarantee similar emotions. Organizers tend to improve the system adding further fan-friendly 
facilities. Due to stadium screens, leaders, security guards, announcers, various stands, logos, trade-marks and symbols, all approved by UEFA, one's individual identity is doomed to blur in the crowd's one. There is also the third zone, that is pubs and clubs, where organizers are not involved; pubs' owners arrange some sort of 'mini zones' on their own because it is profitable for them. Finally, there are all the others who watch matches at home, representatives of the most individual zone. The total number of supporters constitute a quite big crowd expecting to have 'much fun', but what actually counts all in all that is the consumerist cool calculation of organizers.

\section{A nationalist-Patriotic Approach - a Non-Sporting Experience}

In 2012, being hosts of the European football championship, Poles wanted to show Europe they were not worse than others and could win, too. Therefore, they put on national paint underlying the Polish character of the spectacle and the clearly defined role of a 'fan-Pole', who tends to lack realism and identifies the loss or victory of the national team with that of the country itself. It is evident that great entertainment means great emotions, but during the championships I wondered repeatedly if the Poles' expectations were not exaggerated. Were their wishful expectations not a compensatory way of escape from reality? Were the football matches not merely a dramatic manifestation of negative emotions provoking a kind of pseudo-patriotic war against historical enemies? The problem does not regard only Poles; elsewhere football wars really take place. Contemporary sport finds its inspiration in the ideal of a hero or a demigod who is supposed to carry the honor and firmness of the whole nation on his shoulders, and so skills and efficiency of a football player become a metaphor of the dignity and prestige of the state. Thus, sport is no longer only entertainment and competition, but increasingly frequently it has a mission, a really important one. Groups of fans enter political and ideological struggles. They take advantage of the mass character of sporting events to demonstrate their views, while the match is only in the background $[12,13]$. I remember some scenes of Polish fans provoking Russian fans and their absurd historical and patriotic justification. For many of them seeking confrontation at all costs with the fans of the opposite team was the real goal of their participation in the match. In Poland this approach to sporting events has many faces. From anti-Semitic, racial and antigovernment to nationalist and religious. Le Bon wrote [7, p. 17]: By the mere fact that individuals form part of an organized crowd, a person descends several rungs down the ladder of civilization. When isolated, that person may be a cultivated individual; in a crowd, the same person is a barbarian. That is to say a creature acting by instinct. Individuals possess the spontaneity, the violence, the ferocity, and also the enthusiasm and heroism of primitive beings, whom they further tend to resemble by the facility with which they allow themselves to be impressed by words and images (...) and to be induced to commit acts contrary to their most obvious interests and bestknown habits.

The crowd reacts spontaneously, hardly thinks or reflects. Reaction is direct and expressive. Emotions are straightforward. On the one hand, there are shouts, curses, whistles and howls as manifestations of their disapproval or anger; and on the other hand, songs and chants, cries of joy and admiration. The outburst of collective excitement pushes them further - 'we start hugging each other' or 'we start fighting aggressively'. It is obvious that hasty generalization should be avoided. I, myself, am a football supporter and know that among fans there are some people who seek an opportunity to initiate rows and purposely lead to dangerous situations.

What constitutes the wild power of the crowd is, firstly, the great mass that amounts to thousands of people gathered in one stadium, secondly - their anonymity, thirdly deindividualization. A man with a scarf covering his face and hidden in the crowd is only its particle. Therefore, all the forbidden, antisocial, or even criminal acts become permissible, are unpunishable. The crowd is eager to hide these individuals, and in this way, shows its superiority and feels invincible [7, 12, 13]. When emotions reach the maximum intensity, they seek escape. There is an evident analogy with fans-warriors greedy for victory who, like tribal hordes, do not avoid extreme solutions; with time they want real victims and blood. Football atmosphere, speed and unpredictability of the game escalate their violence, which enhanced by the dressing of painted faces, club or national colors and emblems accompanied by unlimited sound and fury, gets 
out of control of the participants themselves. Arthur Koestler, a writer and journalist of Hungarian origin but living in the UK, being a great football supporter never forgot about his 'real' national team - Hungary. He was right when he said that the difference between nationalism and 'football nationalism' consists in the fact that the latter is more deeply rooted in your heart [14].

Such practices in stadiums become common, which means that evolution of the fan is a slow process; international or intercultural reconciliation is more difficult to achieve than to control the most primitive and wildest emotions. There is an urgent need for a defined, at least vaguely, enemy or opponent. Already in the interwar period football clubs were classified by religion or nationality; for example, Arsenal was defined as 'Irish', Ajax Amsterdam and Tottenham London were 'Jewish', 'protestant' was Celtic Glasgow and 'catholic' was Glasgow Rangers. Similar attributions exist also in Polish clubs. In Europe, after the Nazi and Stalin regimes, the spirit of religious and ethnic stigmatization was unacceptable in the public space. However, the attitudes and views did not die; thus they started manifesting themselves in other dimensions of the public space. Probably, in this way the darkest instincts of national demons look for 'scapegoats' and find their arena of activity in football stadiums. It may be a transitory stage of purification, a relatively controlled passage which will lead to a national self-therapy and at the same time is a manifestation of the past and present phobias $[15,16,17]$. Individuals are no longer themselves but become automated and cease to be guided by their will [7].

Here and there some positive signs of changes are already visible. For example, due to the present globalization of football, it is possible to notice a slow process of accepting old enemies, who have been hated for their nationality, religion or color of skin. The success of the French team in 1988 showed that an Afrikaner and an Arab do not have to represent 'diversities' which cannot be overcome.

\section{An Approach Combining the Everyday and Festive Football Varieties}

It is difficult to separate a football festival from Poland's premier league. During such a sporting event as the European Championships, Polish footballers' skills have to be compared with those of other European footballers. Some Polish footballers play in excellent European clubs, but the Polish top clubs are ranked low on the European scale. Are these the grounds on which Poles can rely their aspirations to achieve success on the football arena? Does the key to success lie in our exceptional system of training teenagers? Or in our extraordinary coaches? For years these questions have been raised by sports journalists. Rafał Stec [18] skillfully writes about all the complaints and shortages of the system. It is obvious to every coach, player and conscious supporter that high aspirations have to be firmly grounded in the football players' abilities. Finally, what some people had feared actually happened: Poland did not qualify for the quarter-finals; it means we lost in terms of sport success. It is useless to find consolation in the successful organization of EURO 2012. Neither beautiful and modern but loss-making stadiums, nor another change in the top management of the Polish Football Association will help the Polish team to qualify for the World Cup.

Between great football festivals there is a grey everyday reality. Festivity is useful because it is something extraordinary and has an exceptional impact on supporters. Sports educators and promoters could suggest: let's make sport fun again with all its beneficial psychosocial outcomes [19] for which sport was invented: noble competition, joy and beauty of movement, body and mind health. Football as the most popular sport, especially among children and young people, carries a great responsibility, whose objectives may be neither hedonistic nor patriotic, but health. The author, an academic scholar and health promoter, would like to see in sport and large-scale sporting events an ally in his efforts. However, young spectators of great sporting events are subject to various temptations, sometimes really harmful, which are all around in the football world. For example, the greatest football star of the Polish team, Robert Lewandowski, is a spokesmodel for Coca-Cola, Kuba Błaszczykowski advertises McDonald's, whereas Zbigniew Boniek, a great hero of the Polish football history and the current president of the Polish Football Association, advertises one of the top breweries. These multinationals have accompanied the greatest sporting events for years now. It will not be easy to change the situation in Poland as the cooperation with 
the multinationals is backed by sports organizations like FIFA and the International Olympic Committee. What can parents or health promoters do if they have to oppose such powerful propaganda forces?

All the efforts of parents and teachers to inculcate healthy lifestyle, movement and rational nutrition in adolescents are helpless when confronted with the consumerist attitude of the icons of Polish sport. You do not have to be an expert to realize that the aforementioned manufacturers are the principal culprits in weight gain which leads to overweight and obesity among millions of fans. Not everybody comes to this conclusion in time, but undoubtedly cynicism and hypocrisies of the profit-oriented organizers of large-scale sporting events is omnipresent.

One more digression on the specific attitude of Polish fans during and after EURO 2012. If after another crushing defeat we sing again 'Poles, it's all right', I am asking myself: is it a symptom of generosity or masked frustration? 'We were badly beaten this summer' and we sing that 'it is all right', 'nothing bad happened' and I wonder if this is really a positive symptom of a will to change in the Polish football world. Perhaps it would be better to say that actually something did happen and something must be done about it. Wann et al. write in their publication Sports Fans: The Psychology and Social Impact of Spectators that it depends on who sings: a mature fan who is loyal to his team regardless of the result and is able to criticize if something does not work out and seek better solutions or a fan who supports the team only if it is successful, but when it loses he sneers at it and makes fun of it [20].

\section{Conclusions}

The aim of the paper was to discuss psychosocial aspects of Polish fans' participation in UEFA EURO 2012. The answers to the questions raised at the beginning of the paper can be synthesized in the following way:

- The hedonistic approach to supporting one's team has passed the exam during EURO 2012. Poles are able to enjoy themselves even if the team is not particularly successful. If confronted with the decaying situation of Polish local football league, we actually did well, even the style in which we accepted the defeats of the team.

- The poor performance of the Polish team did not allow the patriotic aspect to develop. However, the dangerous potential which is shifting towards chauvinism and nationalism is present in the Polish stadiums and manifests itself on occasions of Polish league matches. That means that the year 2012 brought not only a sports failure, but also made the problem of civic maturity more explicit. Each generation of fans develops different collective, both positive and negative, expressions of their expectations, behaviors and manifestations of frustration. It was the year when any clear division between sport and politics was blurred. It turned out that the stadium was too tight for fans; when there are anniversaries of historic events, e.g. the Warsaw Uprising or the Independence Day, fans tend to transfer their emotions out of the stadium and manifest them on the streets. In 2012 football got dangerously close to politics.

- Wishful thinking is the prevailing approach to performances of Poland's team. Poles are not able to see the difference between a festive time like UEFA EURO 2012 and the insipid Polish premier league. In addition, Poles are not able to make advantage of the promotional dimension of sport and use it to promote healthy and active lifestyle of young generations of Poles. Additionally, the protagonists of the previous football teams undermine the public confidence and trust in them, and they cease to be good models of positive sporting behavior and become anti-heroes in TV commercials.

\section{References}

1. Schechner R. Przyszłość rytuału, trans. T. Kulikowski [in Polish] [The future of a ceremonial]. Warszawa: Oficyna Wydawnicza Volumen; 2000.

2. Huizinga J. Homo ludens: zabawa jako źródło kultury, trans. M. Kurecka and W. Wirpsza [in Polish] [Homo ludens: game as an origin of culture]. Warszawa: Czytelnik; 1985.

3. Eastmen S, Riggs K. Televised Sports and Ritual: Fan Experiences. Sociol Sport J 1994;11:249-274. 
4. Spinrad W. The Function of Spectator Sports. In: G. Luschen G, Sage G, editors. Handbook of Social Science of Sport. Champagne, IL: Stipes; 1981, 354-365.

5. Hocking J. Sports and Spectators: Intra-audience Effects. J Commun 1982;32:100-108.

6. Grad J. Problem karnawalizacji kultury współczesnej [in Polish] [Issue of carnivalisation of a contemporary culture] In: Grad J, Mamzer H, editors. Ludyczny wymiar kultury. Człowiek i Społeczeństwo [Popular dimension of a culture. A Man and a Society] vol. 22. Poznań: UAM; 2004.

7. Le Bon G. Psychologia tłumu, trans. B. Kaprocki [in Polish] [Crowd Psychology]. Warszawa: PWN; 1986.

8. Allison M. The Game: A Participant Observation Study. Journal of Sport Behavior 1979;2:93-102.

9. Caillois R. Żywioł $i$ ład, trans. A. Tatarkiewicz [in Polish] [Chaos and order]. Warszawa: PIW; 1973.

10. Mann L. Sports Crowds and the Collective Behavior Perspective. In: Goldstein J. editor. Sport, Games and Play: Social and Psychological Viewpoints. Hillsdale, NJ: Laurence Earlbaum; 1989, 229-327.

11. Branscombe N, Wann D. Role of Identification with a Group, Arousal, Categorization Processes and Self-Esteem in Sports Spectator Aggression. Hum Relat 1992;45:1013-1033.

12. Boire J. Collective Behavior in Sport. Review of Sport and Leisure 1980;25:2-45.

13. Jacobson B. The Social Psychology of the Creation of a Sports Fan Identity: A Theoretical Review of the Literature, University of Connecticut, The Online Journal of Sport Psychology 2003.

14. Buruma I. Football Nationalism after: Policy Innovations, Carnegie Council for Ethics in International Affairs, Project Syndicate, July 14, 2008 [www. policyinnovation,org>ideas>commentary] [accessed 2012]

15. Madrigal R. Cognitive and Affective Determinants of Fan Satisfaction with Sporting Event Attendance. $J$ Leisure Res 1995;27:205-227.

16. Bensimon M, Bodner E. Playing With Fire: The Impact of Football Game Chanting on Level of Aggression. J Applied Social Psychology 2011;41:2421-2433. doi: 10.1111/j.1559-1816.2011.00819.x

17. Allison L. Sport and Nationalism. In: Coakley J, Dunning E, editors. Handbook of Sports Studies. London: Sage; 2000, 344-355.

18. Stec R. Piłka sss...kopana" [in Polish] [A... kicked ball]. Tygodnik Powszechny 43 dated 21.10.2012, p.12.

19. Matusewicz C. Widowisko sportowe. Analiza psychospołeczna [in Polish] [A sports show. A psychosocial analysis]. Warszawa: AWF; 1990.

20. Wann D, Melnick M, Russell G, Page D. Sports Fans: The Psychology and Social Impact of Spectators. New York, NY: Routeledge; 2001. 